\title{
Nanoscale Ordering and Depolymerization of Calcium Silicate Hydrates in Presence of Alkalis
}

\section{Supporting Information}

\author{
Nishant Garg, ${ }^{1}$ V. Ongun Özçelik, ${ }^{1}$ Jørgen Skibsted, ${ }^{2}$ and Claire E. White ${ }^{1 *}$ \\ ${ }^{1}$ Department of Civil and Environmental Engineering and Andlinger Center for Energy and the \\ Environment, Princeton University, Princeton, U.S.A. \\ ${ }^{2}$ Department of Chemistry and Interdisciplinary Nanoscience Center (iNANO), Aarhus University, \\ Aarhus, Denmark
}

\footnotetext{
* Corresponding author: Phone: +1 609258 6263, Fax: +1 609258 2799, Email: whitece@princeton.edu Postal address: Department of Civil and Environmental Engineering, Princeton University, Princeton NJ 08544, U.S.A.
} 


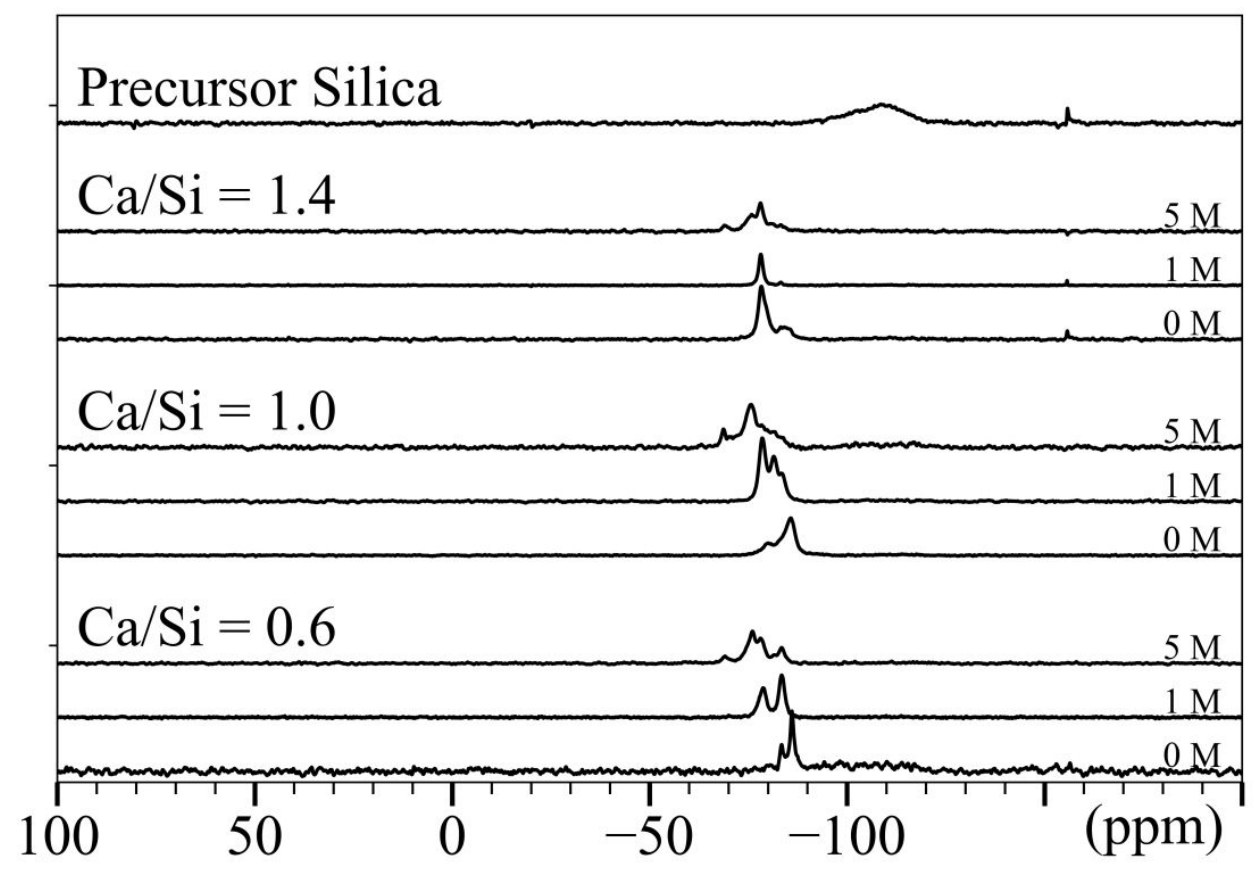

Figure S1: ${ }^{29} \mathrm{Si}$ MAS NMR spectra (wide range) of C-(N)-S-H gels synthesized in varying concentrations of $\mathrm{NaOH}$ solutions at listed $\mathrm{Ca} / \mathrm{Si}$ ratios along with precursor silica used to synthesize these gels. 


$$
\mathrm{Ca} / \mathrm{Si}=0.6
$$

a)

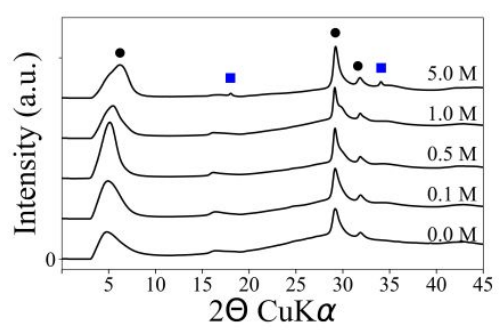

b)

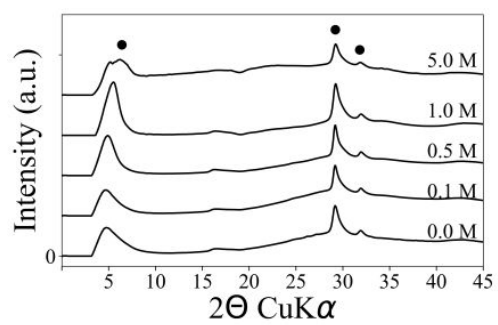

c)

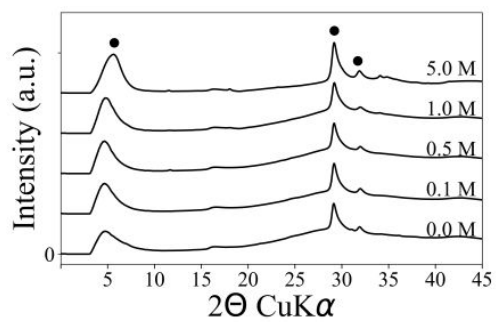

$\mathrm{Ca} / \mathrm{Si}=1.0$
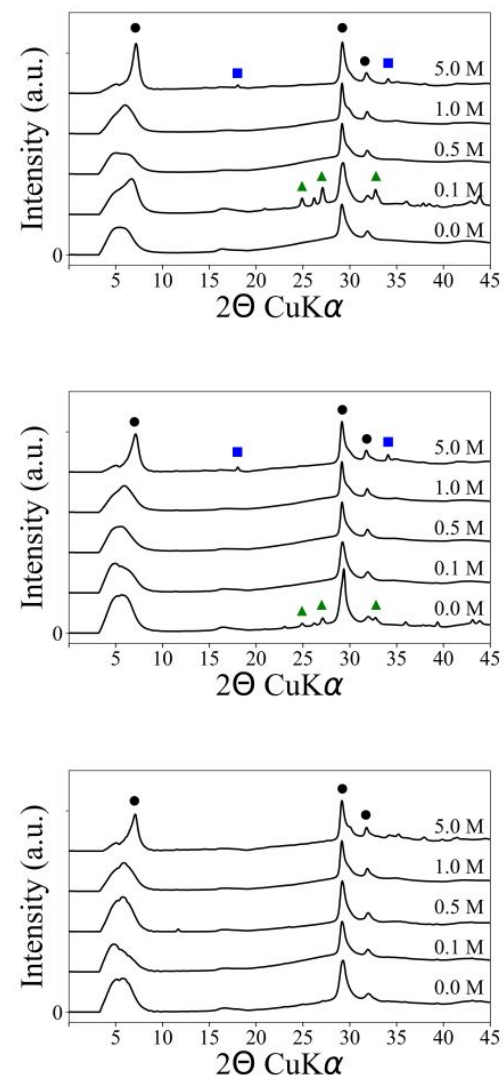

$\mathrm{Ca} / \mathrm{Si}=1.4$
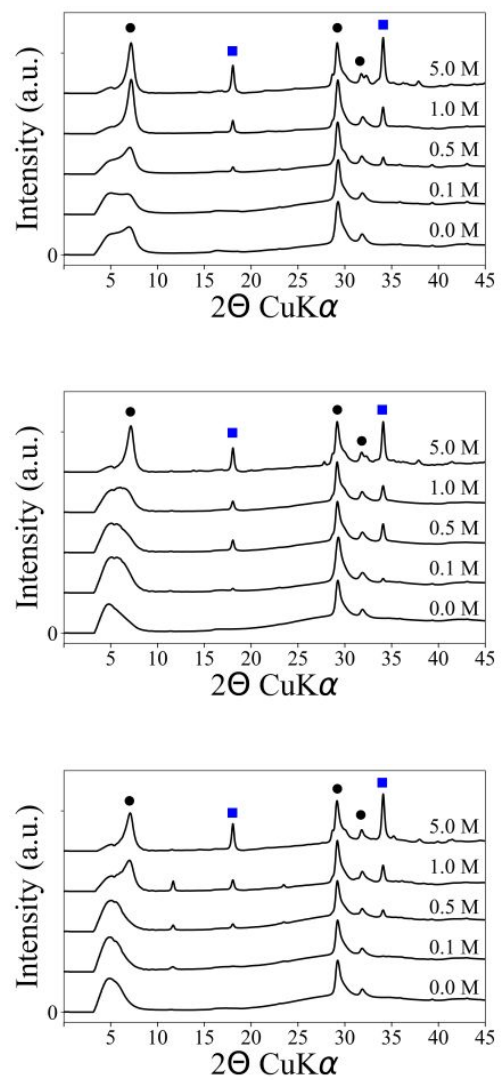

Figure S2: XRD patterns of synthetic C-(N)-A-S-H gels with a) $\mathrm{Al} / \mathrm{Si}=0.0, b)=\mathrm{Al} / \mathrm{Si}=0.05$, and c) $\mathrm{Al} / \mathrm{Si}=0.1$ synthesized in listed concentrations of $\mathrm{NaOH}$ and $\mathrm{Ca} / \mathrm{Si}$ ratios. Black circles $(\bullet)$ refer to the $\mathrm{C}$ (N)-A-S-H gel whose Bragg peaks match that of poorly crystalline $\mathrm{C}-\mathrm{S}-\mathrm{H}(\mathrm{I})\left(\mathrm{CaO} \cdot \mathrm{SiO}_{2} \cdot \mathrm{H}_{2} \mathrm{O}, \mathrm{PDF} \# 00-\right.$ 034-0002). Blue squares ( $\bullet$ ) refer to $\mathrm{Ca}(\mathrm{OH})_{2}$ (PDF \#00-001-1079), green triangles $(\Delta)$ refer to $\mathrm{CaCO}_{3}$ (PDF \#00-024-0030). In all of the above synthetic gels, the only secondary phase is calcium hydroxide which is predominantly present in the gels with a high $\mathrm{Ca} / \mathrm{Si}$ ratio of 1.4 and synthesized in high alkali concentrations. The tertiary phase calcium carbonate is only present in 2 out 45 gels. The diffraction patterns were measured using synchrotron radiation $(\lambda=0.2115 \AA)$ but have been converted to $\mathrm{K} \alpha$ radiation of copper to aid comparison with literature data. 


\begin{tabular}{|c|c|c|c|c|}
\hline Sample \# & $\mathrm{Ca} / \mathrm{Si}$ & $\mathbf{A} \mathbf{l} / \mathbf{S i}$ & $\mathrm{NaOH}$ & Basal Spacing ( $\AA$ ) \\
\hline 1 & \multirow{5}{*}{0.6} & \multirow{5}{*}{0.0} & 0.0 & - \\
\hline 2 & & & 0.1 & - \\
\hline 3 & & & 0.5 & - \\
\hline 4 & & & 1.0 & 16.1 \\
\hline 5 & & & 5.0 & 14.3 \\
\hline 6 & \multirow{5}{*}{1.0} & \multirow{5}{*}{0.0} & 0.0 & 14.7 \\
\hline 7 & & & 0.1 & 13.1 \\
\hline 8 & & & 0.5 & 14.0 \\
\hline 9 & & & 1.0 & 14.7 \\
\hline 10 & & & 5.0 & 12.3 \\
\hline 11 & \multirow{5}{*}{1.4} & \multirow{5}{*}{0.0} & 0.0 & 12.7 \\
\hline 12 & & & 0.1 & 13.1 \\
\hline 13 & & & 0.5 & 12.5 \\
\hline 14 & & & 1.0 & 12.3 \\
\hline 15 & & & 5.0 & 12.3 \\
\hline 16 & \multirow{5}{*}{0.6} & \multirow{5}{*}{0.05} & 0.0 & - \\
\hline 17 & & & 0.1 & - \\
\hline 18 & & & 0.5 & - \\
\hline 19 & & & 1.0 & 16.1 \\
\hline 20 & & & 5.0 & 14.3 \\
\hline 21 & \multirow{5}{*}{1.0} & \multirow{5}{*}{0.05} & 0.0 & - \\
\hline 22 & & & 0.1 & - \\
\hline 23 & & & 0.5 & - \\
\hline 24 & & & 1.0 & - \\
\hline 25 & & & 5.0 & - \\
\hline 26 & \multirow{5}{*}{1.4} & \multirow{5}{*}{0.05} & 0.0 & 15.7 \\
\hline 27 & & & 0.1 & 15.9 \\
\hline 28 & & & 0.5 & 15.8 \\
\hline 29 & & & 1.0 & 14.9 \\
\hline 30 & & & 5.0 & 12.4 \\
\hline 31 & \multirow{5}{*}{0.6} & \multirow{5}{*}{0.1} & 0.0 & 15.4 \\
\hline 32 & & & 0.1 & 15.4 \\
\hline 33 & & & 0.5 & 15.4 \\
\hline 34 & & & 1.0 & 14.9 \\
\hline 35 & & & 5.0 & 12.5 \\
\hline 36 & \multirow{5}{*}{1.0} & \multirow{5}{*}{0.1} & 0.0 & - \\
\hline 37 & & & 0.1 & 15.6 \\
\hline 38 & & & 0.5 & 15.7 \\
\hline 39 & & & 1.0 & 14.6 \\
\hline 40 & & & 5.0 & 12.4 \\
\hline 41 & \multirow{5}{*}{1.4} & \multirow{5}{*}{0.1} & 0.0 & - \\
\hline 42 & & & 0.1 & 15.4 \\
\hline 43 & & & 0.5 & 15.4 \\
\hline 44 & & & 1.0 & 12.6 \\
\hline 45 & & & 5.0 & 12.5 \\
\hline
\end{tabular}

Table S1: Experimental basal spacings obtained from the XRD patterns (Figure S2). In selected samples, a distinct $\mathrm{d}_{002}$ peak could not be separated from interference/artifacts due to the beam stop and hence for those samples no basal spacing is reported. 

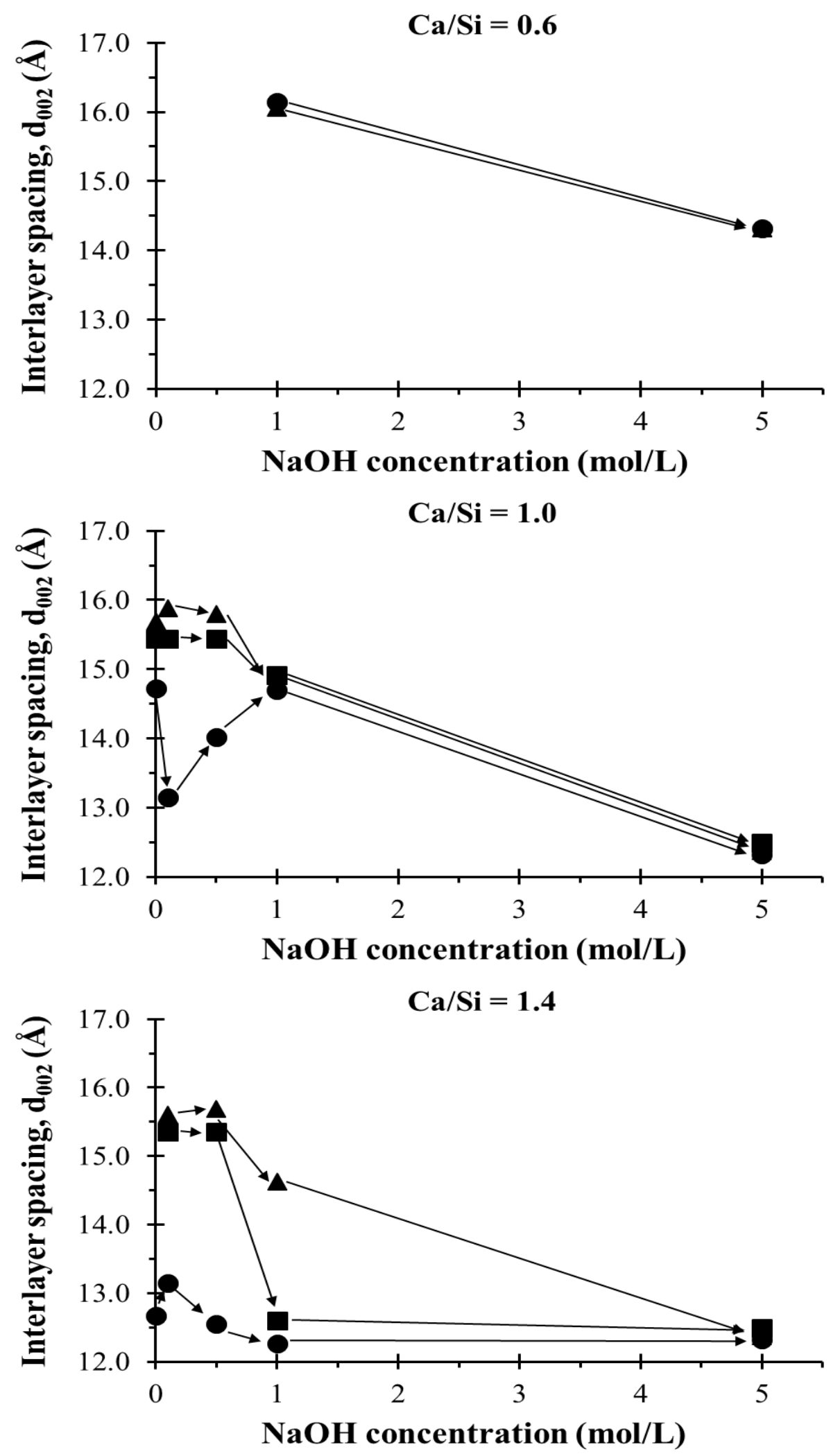

Figure S3: Experimental basal spacings (as reported in Table S1) plotted as a function of $\mathrm{NaOH}$ concentration used for the synthesis of the C-(N)-A-S-H gels, at listed $\mathrm{Ca} / \mathrm{Si}$ ratios. 
a)

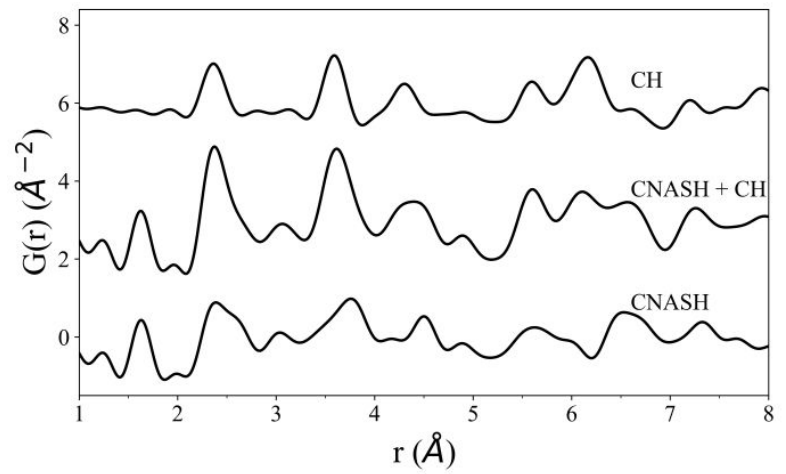

b)

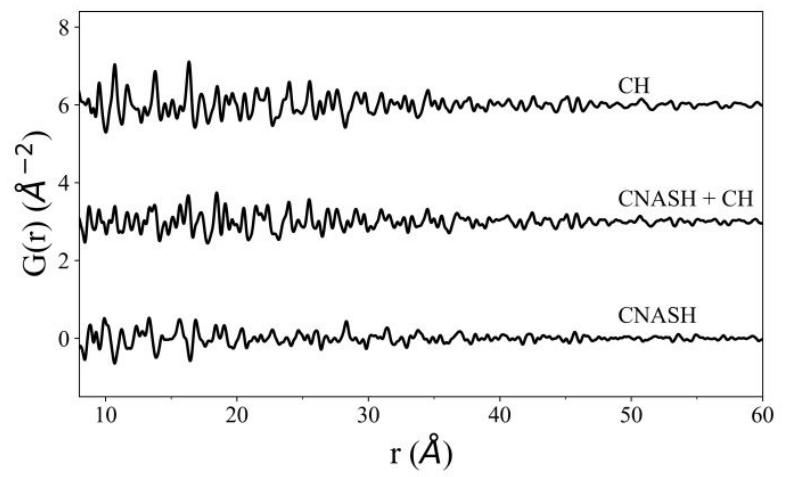

c)

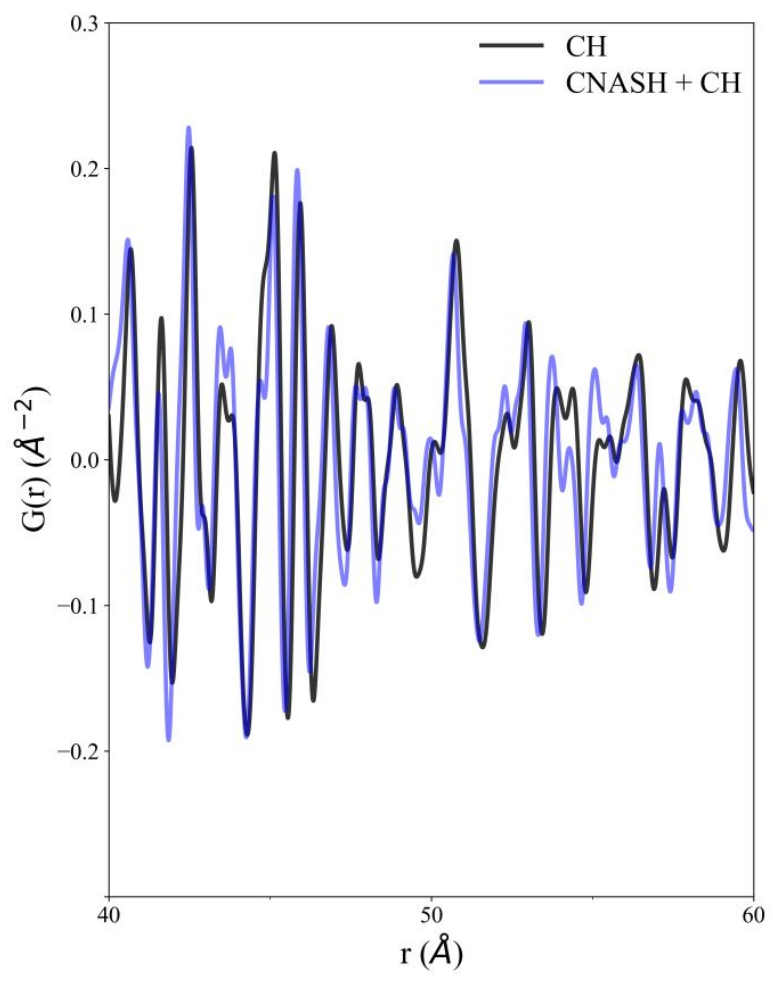

Figure S4: X-ray PDF of a C-(N)-A-S-H gel (CNASH, $\mathrm{Ca} / \mathrm{Si}=1.4, \mathrm{Al} / \mathrm{Si}=0.1, \mathrm{NaOH}=5 \mathrm{M})$ before (denoted $\mathrm{CNASH}+\mathrm{CH}$ ) and after (denoted $\mathrm{CNASH})$ the removal of calcium hydroxide PDF $(\mathrm{CH}$, shown on top). (a) shows the low $\mathrm{r}$ region (1 to $8 \AA$ ), (b) shows the long range $\mathrm{r}$ region (8 to $60 \AA$ ), and (c) shows the comparison of two selected PDFs at the high $r$ region (40 to $60 \AA$ ). 
a) $\mathrm{Ca} / \mathrm{Si}=0.6$
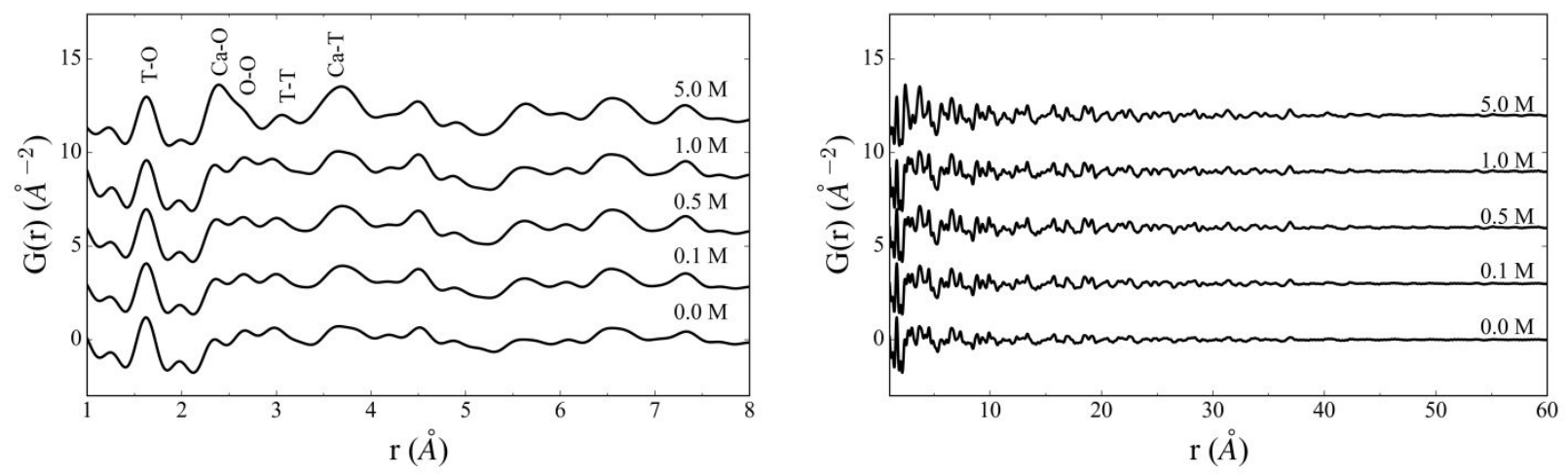

b) $\mathbf{C a} / \mathbf{S i}=\mathbf{1 . 0}$
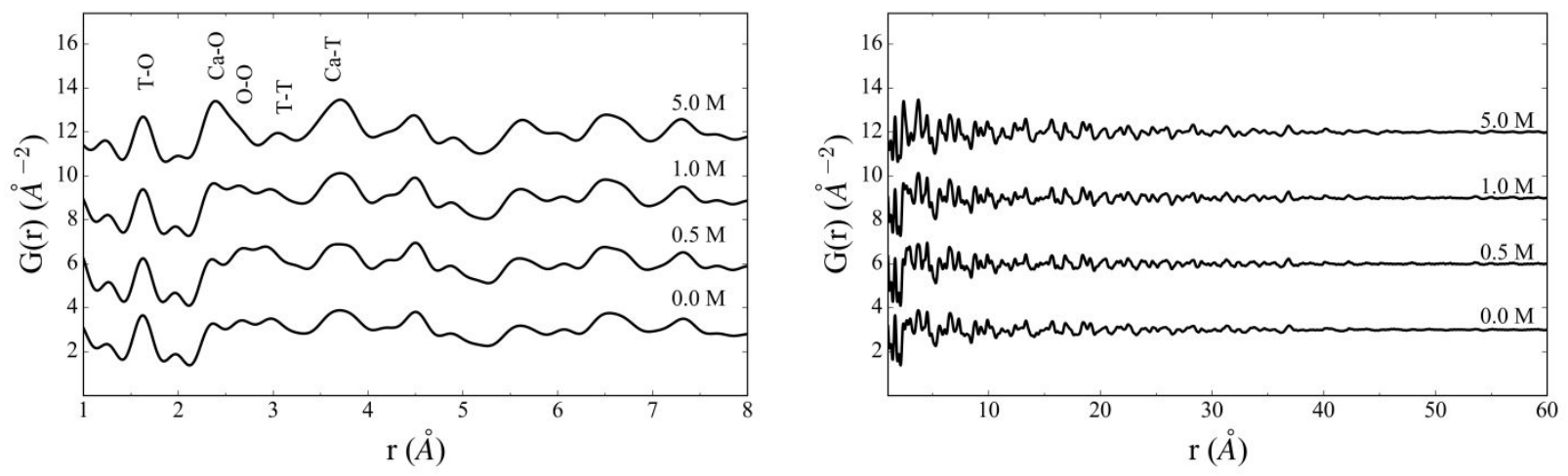

c) $\mathrm{Ca} / \mathrm{Si}=1.4$
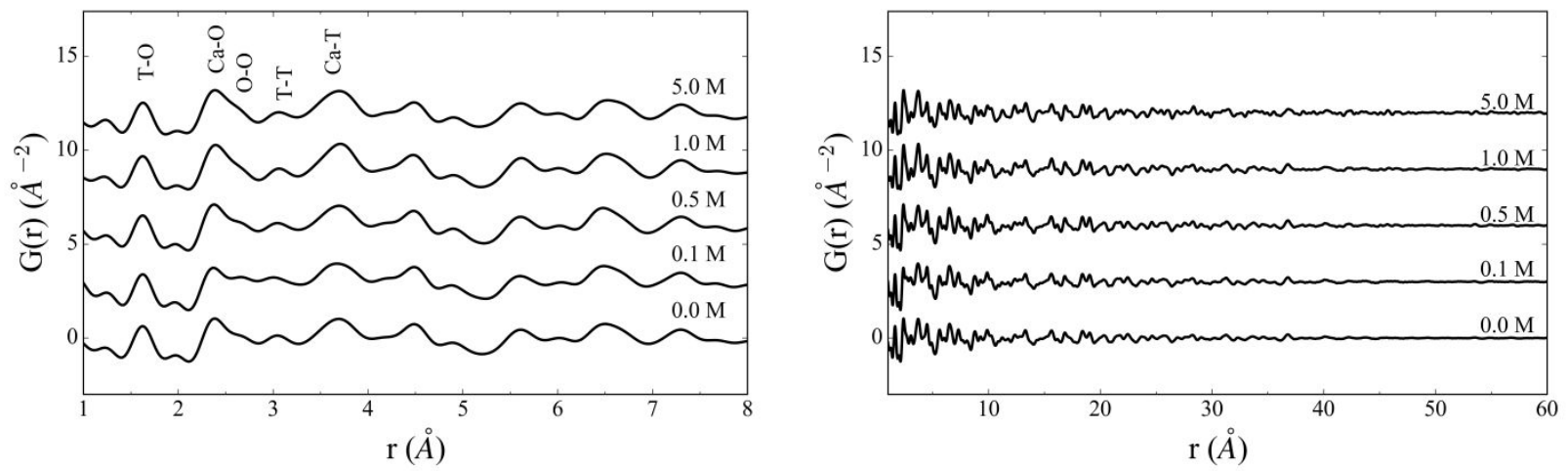

Figure S5: X-ray PDF of C-(N)-A-S-H gels of noted $\mathrm{Ca} / \mathrm{Si}$ ratios synthesized with solutions of listed $\mathrm{NaOH}$ concentrations $(0.0-5.0 \mathrm{M})$ at $\mathrm{Al} / \mathrm{Si}$ of 0.0 after removal of contributions from the calcium hydroxide PDF as explained in the methods section. Left column shows the low $r$ region $(1$ to $8 \AA)$ and the right column shows the long range $r$ region ( 8 to $60 \AA$ ). The $0.1 \mathrm{M}$ sample for $\mathrm{b}$ ) $\mathrm{Ca} / \mathrm{Si}=1.0$ has been omitted as it suffered from some carbonation. 
a) $\mathrm{Ca} / \mathrm{Si}=0.6$
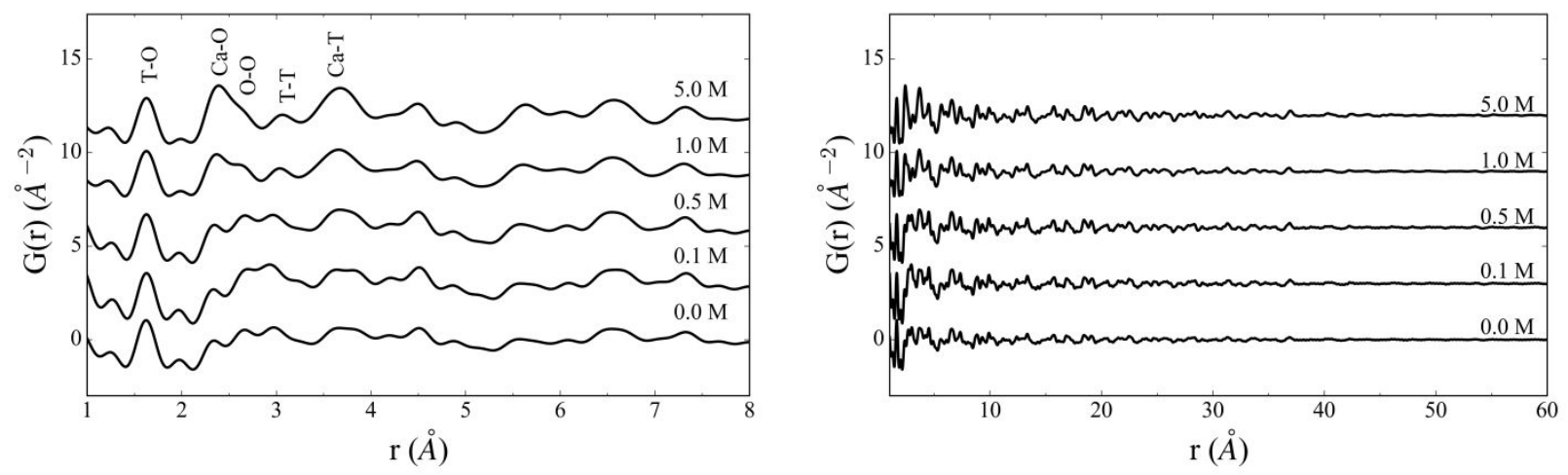

b) $\mathbf{C a} / \mathbf{S i}=\mathbf{1 . 0}$
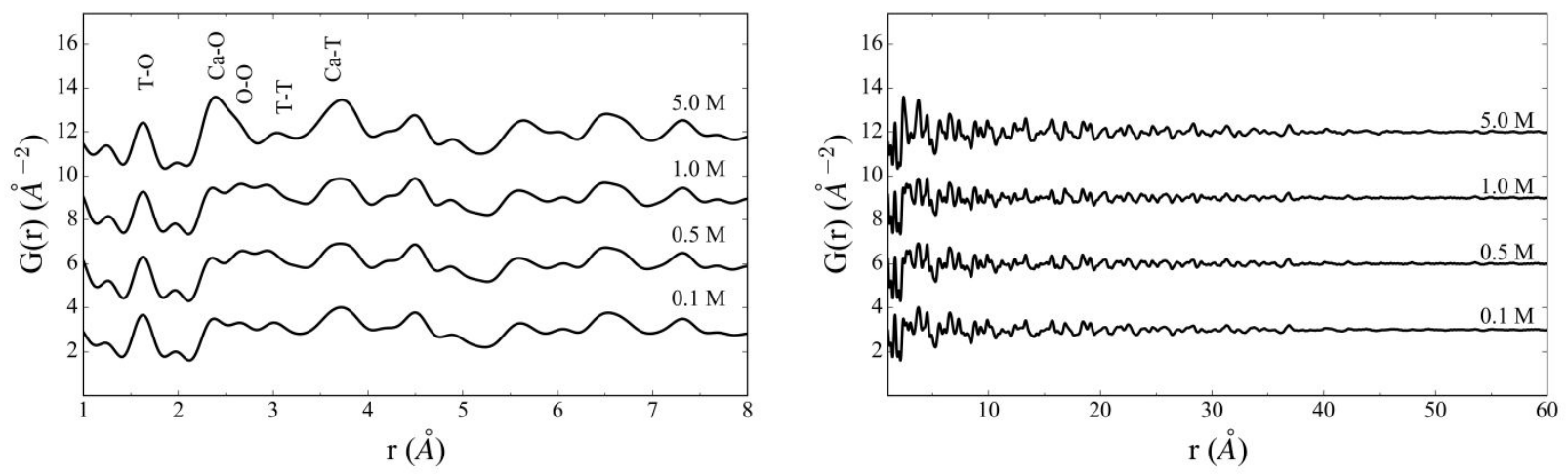

c) $\mathrm{Ca} / \mathrm{Si}=1.4$
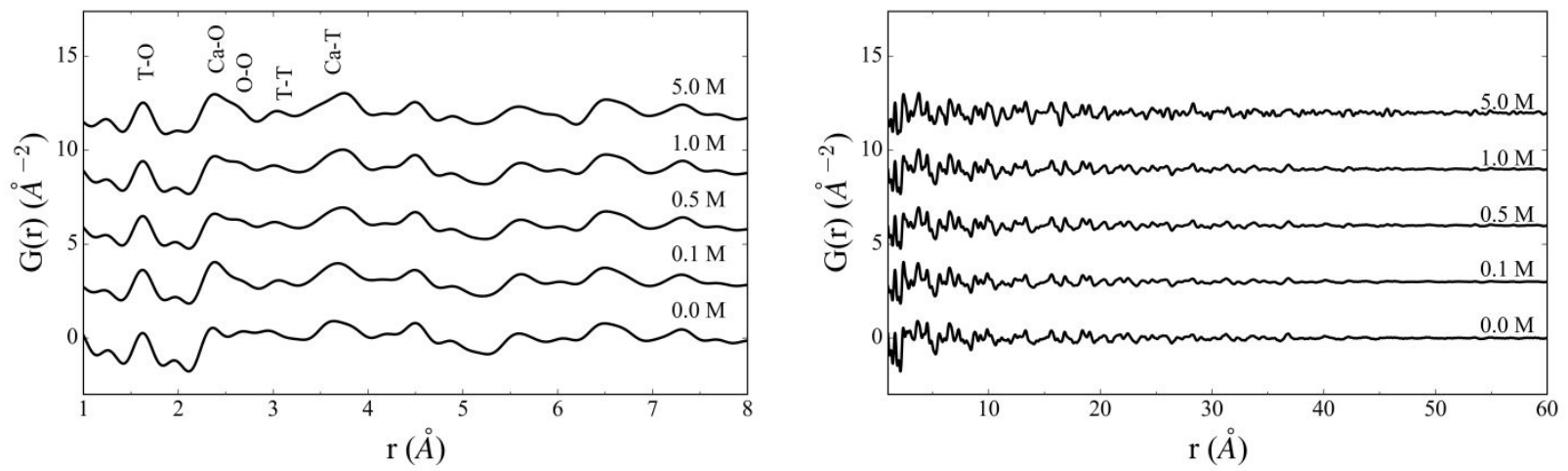

Figure S6: X-ray PDF of C-(N)-A-S-H gels of noted $\mathrm{Ca} / \mathrm{Si}$ ratios synthesized with solutions of listed $\mathrm{NaOH}$ concentrations $(0.0-5.0 \mathrm{M})$ at $\mathrm{Al} / \mathrm{Si}$ of 0.05 after removal of contributions from the calcium hydroxide PDF as explained in the methods section. Left column shows the low $r$ region $(1$ to $8 \AA)$ and the right column shows the long range $r$ region ( 8 to $60 \AA$ ). The $0.0 \mathrm{M}$ sample for $\mathrm{b}$ ) $\mathrm{Ca} / \mathrm{Si}=1.0$ has been omitted as it suffered from some carbonation. 
a) $\mathrm{Ca} / \mathrm{Si}=0.6$
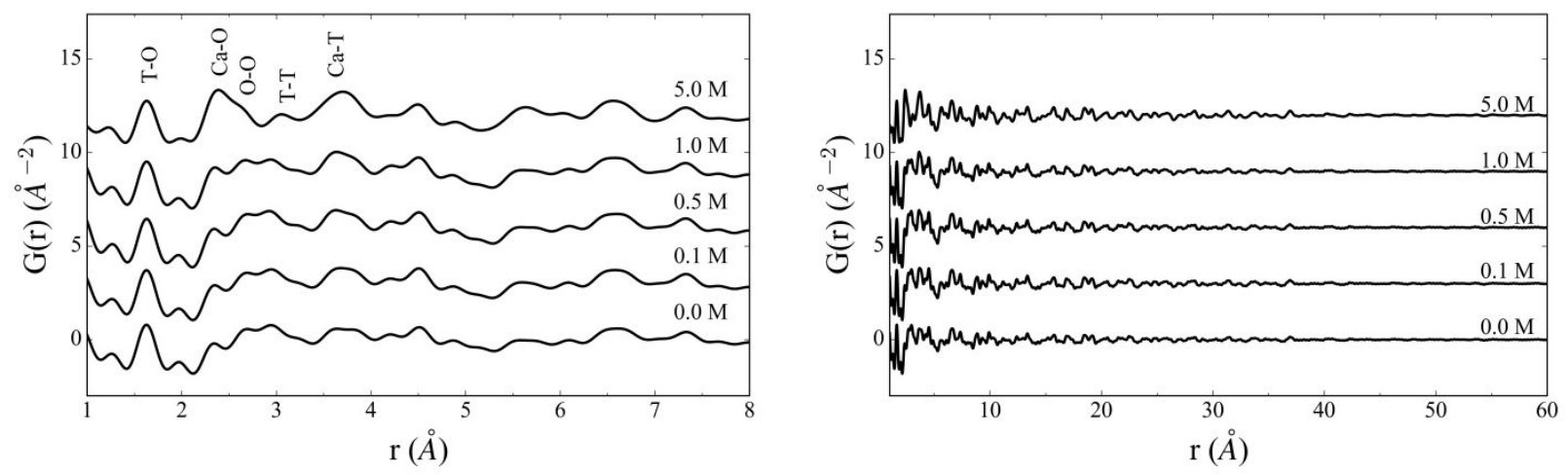

b) $\mathrm{Ca} / \mathrm{Si}=\mathbf{1 . 0}$
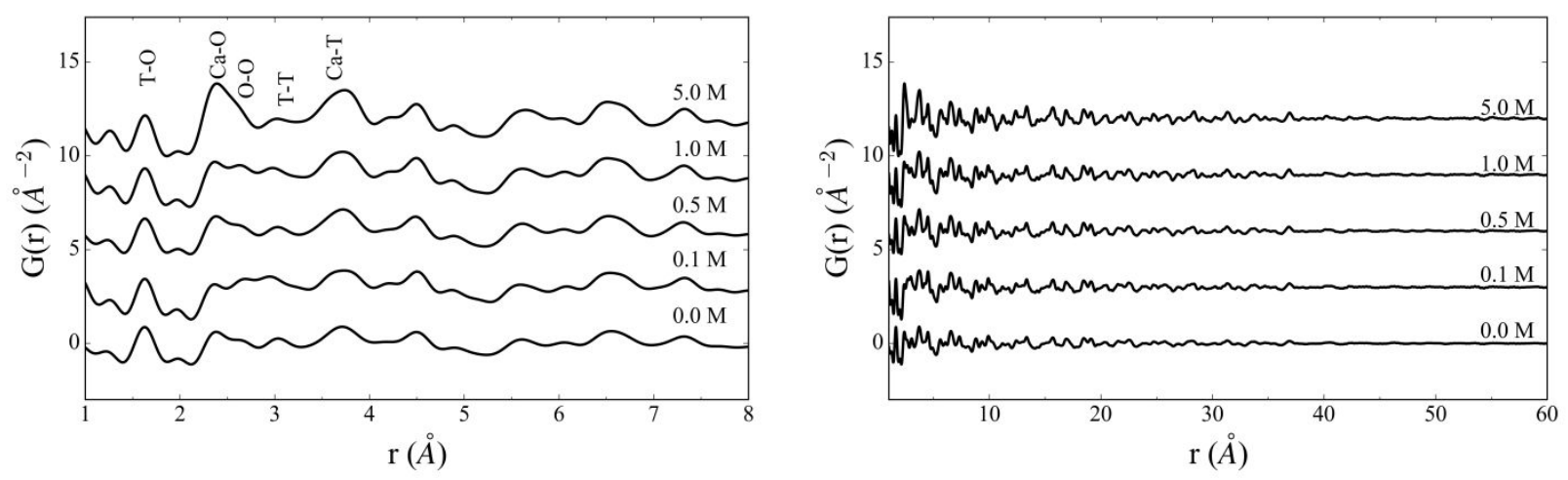

c) $\mathrm{Ca} / \mathrm{Si}=1.4$
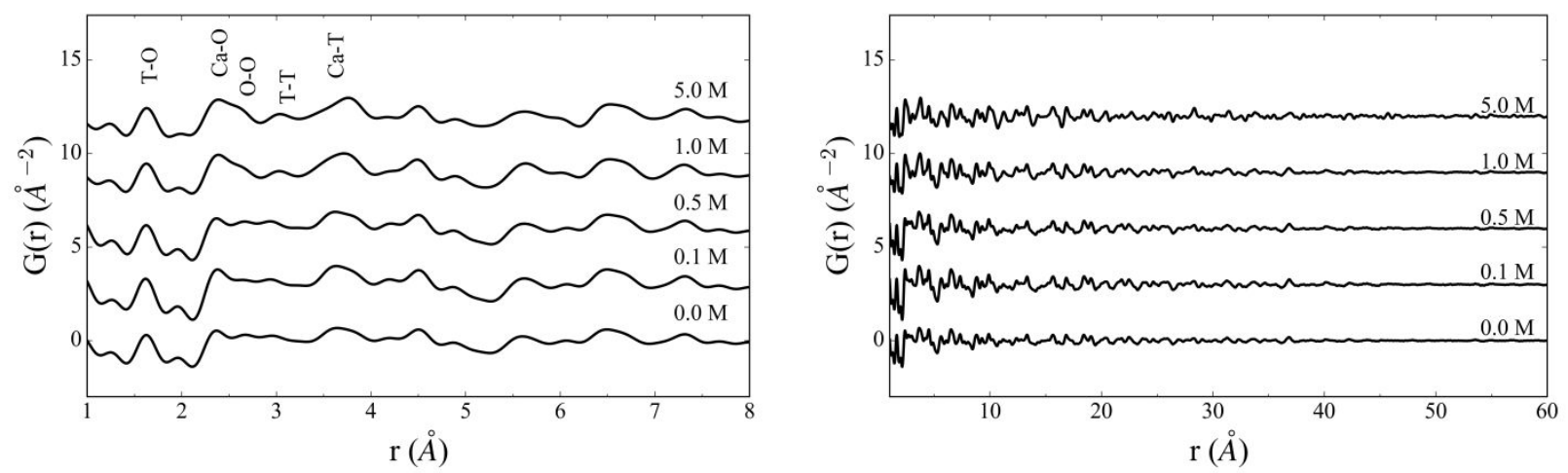

Figure S7: X-ray PDF of C-(N)-A-S-H gels of noted $\mathrm{Ca} / \mathrm{Si}$ ratios synthesized with solutions of listed $\mathrm{NaOH}$ concentrations $(0.0-5.0 \mathrm{M})$ at $\mathrm{Al} / \mathrm{Si}$ of 0.1 after removal of contributions from the calcium hydroxide PDF as explained in the methods section. Left column shows the low $r$ region (1 to $8 \AA$ ) and the right column shows the long range $r$ region (8 to $60 \AA$ ). 